\title{
ROLE OF PUBIS IN SEXUAL DIMORPHISM OF HIP BONE - A MORPHOMETRIC STUDY IN NORTH INDIAN POPULATION
} Kanika Sachdeva *1, Rajan K Singla ${ }^{2}$, Gurdeep Kalsey ${ }^{3}$.

${ }^{* 1}$ Associate Professor, Department of Anatomy, SGRDIMSAR, Amritsar, Punjab, India.

${ }^{2}$ Professor, Department of Anatomy, Government Medical College, Patiala, Punjab, India.

${ }^{3}$ Retired Professor \& Head, Department of Anatomy, Government Medical College, Amritsar, Punjab, India.

\section{ABSTRACT}

Background: Different bones of the human skeleton present age-, sex- and race-related dissimilarities, so that using visual criteria \& metric techniques, age, sex, and race of an individual can be estimated from these bones. One such bone is the hip bone whose characteristic morphology makes it interesting from anatomical, anthropological, and forensic point of view. Its features are important not only for the anatomist but also for the anthropologist, for population studies \& for forensic experts for specimen recognition and gender determination of skeletal remains. The three constituent parts of hip bone i.e ilium, ischium and pubis depict different gender specific features. The pubis showing pubertal changes first of all are being considered in this article. Its different parameters will be definitely helpful to anatomists, anthropologists \& forensic experts in their respective fields. Materials and Methods: The present study was conducted on 100 adult undamaged human hip bones, (M:F=80:20, $\mathrm{R}: \mathrm{L}=50: 50$ ) obtained from the Department of Anatomy, Government Medical College, Amritsar. The various dimensions of the pubis measured were (1) Mid Pubic Width, (2) Length of Pubic Crest, (3) Length of Pubic Bone, (4) Length of Pubic bone upto acetabulum. The observations were statistically evaluated to find out sex $\&$ side related differences.

Results: All the pubic parameters measured were significantly larger in female bones as compared to male bones, except the mid pubic width. However no significant side specific pattern could be determined in either sex.

Conclusions: There is a relative paucity of region specific data for the various parameters of pubis in the accessible literature. Thus the present study advocates the significance of pubis in sexual dimorphism, for sex determination $\&$ provides reference values for the North India region.

KEY WORDS: Pubis, Hip Bone, Anthropometry, Sexual Dimorphism, Sex determination.

Corresponding Author: Dr Kanika Sachdeva, Chander Niwas, 61, Lawrence Road, Amritsar-143001, Punjab, India.+91-9888284878 E-Mail: kanikadr.sarang@yahoo.com

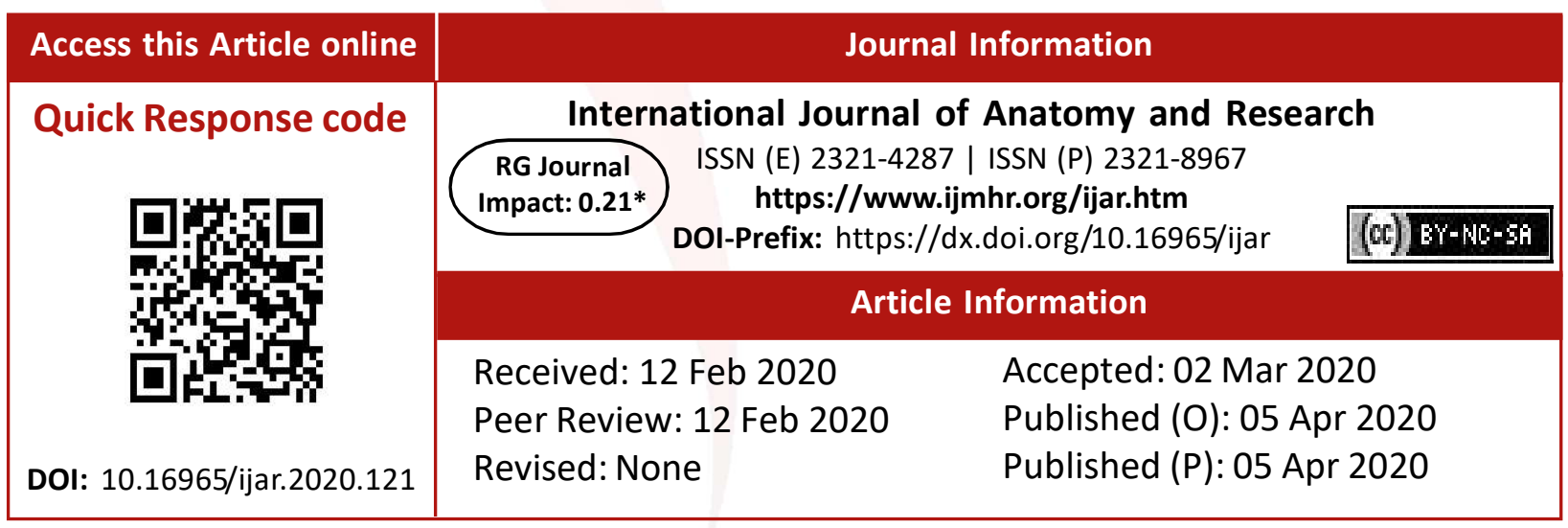

\section{INTRODUCTION}

Identification of fresh dead bodies is relatively easier than that of decomposed and skeletonized human remains [1]. Also, it is easier to identify gender of bones if the skeletal remains found are complete. However, in cases of fragmented and incomplete skeletal framework, sexing of remains becomes a major problem [2]. Nevertheless, the bones are influenced by various factors, like age, sex, race, genetics, and environmental conditions. Anatomists and forensic experts can give expert opinion in the medicolegal cases regarding sex and age of the individual from the available skeletal remains 
found under suspicious conditions. [3-5].

Several metric and non-metric sex differences in skeletal component are evident amongst different populations which can be helpful in determination of sex. [6] The introduction of metric methods has definitely provided the simplicity and accuracy to determine the sex of skeletal remains [7].

For sexing of human skeleton majority of the experts regard the hip bone as providing the highest accuracy levels [8]. In 1891, Matthew and Billings first attempted to use measurements and indices to determine or confirm the sex of pelves, as mentioned by Hoyme [9].

The human hip bone is considered as one of the most reliable bones for sex determination when compared to any other bones in the body [10]. The sexual dimorphism of hip bone has been attributed to be a special adaptation in the females for childbearing. Consequently, awareness of the normal proportions of the hip bone in both the sexes will also help in early recognition of uncertain sex by forensic experts [11].

Different components of hip bone viz ilium, ischium \& pubis have different levels of accuracy in sex determination $[12,13]$. Out of these the pubic part of hip bone has been advocated as the most significant predictors of the sex $[13,14]$. Accuracy of sex determination from different parameters of pubic bone varies from $81 \%$ to $95 \%[15-17]$. So this study was designed to throw some light on different parameters of pubic component of hip bone and their importance in sex determination.

\section{MATERIALS AND METHODS}

The present study was performed on a set of 100 undamaged hip bones (Male: Female $=80: 20$ and Right: Left $=50: 50$ ) obtained from the Department of Anatomy, Government Medical College, Amritsar. The bones were intact and showed no pathological changes. For each of these hip bones, four parameters of the Pubis were measured: Mid Pubic Width, Length of the pubic crest, Length of pubic bone and length of the pubic bone upto acetabulum. The measurements were taken with the help of a vernier calipers. The steps of taking these measurements are given below:

Mid pubic width: It was measured with vernier caliper as the shortest distance from the middle of the symphyseal surface of the body of pubis to the obturator foramen [18] (CD in Fig. 1).

Length of pubic crest: It was measured with vernier calipers as the length of the superior border of the body of pubis, from symphyseal surface upto pubic tubercle (AB in Fig. 1).

Length of pubic bone: It was measured with vernier calipers as the distance of the central point of the acetabulum from the upper end of symphyseal surface of the body of pubis [19] (PO in Fig. 2). For locating the central point of acetabulum, Schultz [20] described that frequently there is an irregularity both in the acetabulum and inside the pelvis. He also described a change in thickness of bone which may be seen by holding the bone upto the light. He further mentioned that often there is a notch in the border of the articular surface in the acetabulum. However in the present study, the first method; i.e similar irregularity both on inner and outer surface of acetabulum was taken as the central point to determine the length of pubic bone.

Fig. 1: Part of Left Sided Hip Bone Showing Points to measure. Mid Pubic Width (CD) \& Length of Pubic Crest (AB).

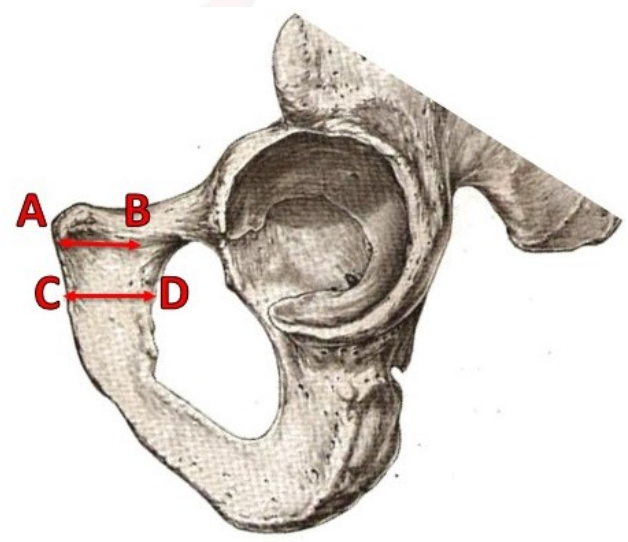

Length of pubic bone upto acetabulum: It was taken with vernier calipers as the distance from upper medial end of pubic bone to the nearest edge of the acetabulum (PL in Fig. 2).

All the observations were compiled and tabulated and statistically analysed. Values thus obtained were tabulated and statistically analysed using SPSS Version 17. Mean, standard deviation and SE of mean in both the sexes were calculated for all the pubic dimensions. Independent Student's t-test for equality of means was applied to find out the significance 
of the differences between the means for males and females.

Fig. 2: Part of Left Sided Hip Bone Showing Points to measure. Length of Pubis (PO) \& Length of Pubis upto acetabulum (PL)

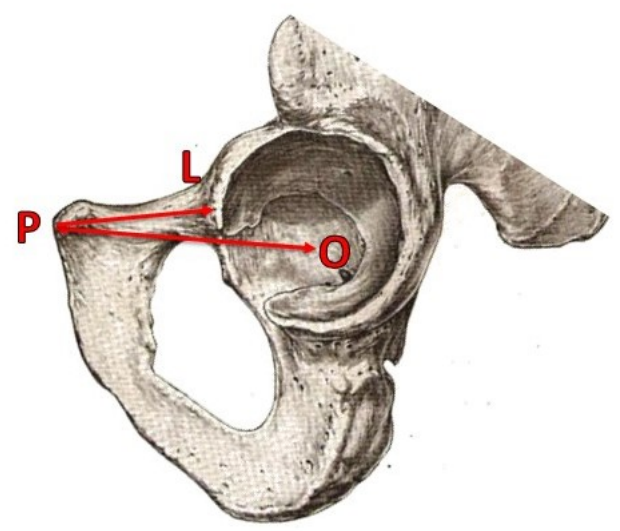

\section{RESULTS}

In the present study an attempt has been made to find out if there exists any significant difference with respect to sex or side in the various parameters of the pubis of Hip Bone. From the observations which have been compiled in Table 1 , it can be seen that in the North Indian pubic bones, except the midpubic width, all other three parameters i.e. Length of pubic crest, Length of pubic bone and length of pubic bone upto acetabulum; are significantly longer in females as compared to males. However no significant definitive pattern has been seen with respect to side, as results are variable in all parameters, both in males and females.

Table 1: Calculated Mean values, Standard deviation and Range for various parameters studied in both sexes on both sides.

\begin{tabular}{|c|c|c|c|c|c|c|c|}
\hline \multirow[t]{2}{*}{ Sr. No. } & \multirow[t]{2}{*}{ Pubic Parameter } & \multicolumn{2}{|c|}{$\begin{array}{l}\text { Males }(\mathrm{N}=80) \\
\text { Mean } \pm \text { S.D. }\end{array}$} & \multicolumn{2}{|c|}{$\begin{array}{c}\text { Females }(\mathrm{N}=20) \\
\text { Mean } \pm \text { S.D. }\end{array}$} & \multicolumn{2}{|c|}{ P-value } \\
\hline & & Right & Left & Right & Left & For Sex & For Side \\
\hline 1 & Mid pubic Width & $\begin{array}{c}3.06 \pm 0.43 \\
(2.10-3.94)\end{array}$ & $\begin{array}{c}3.09 \pm 0.42 \\
(2.02-3.92)\end{array}$ & $\begin{array}{c}2.90 \pm 0.35 \\
(2.32-3.43)\end{array}$ & $\begin{array}{l}2.94 \pm 0.38 \\
(2.43-3.60)\end{array}$ & 0.148 & $\begin{array}{l}0.619(\mathrm{M}) \\
0.680(\mathrm{FM})\end{array}$ \\
\hline 2 & Length of Pubic Crest & $\begin{array}{c}2.02 \pm 0.50 \\
(1.24-3.55)\end{array}$ & $\begin{array}{c}2.07 \pm 0.45 \\
(1.28-3.56)\end{array}$ & $\begin{array}{c}2.81 \pm 0.27 \\
(2.34-3.21)\end{array}$ & $\begin{array}{c}2.79 \pm 0.36 \\
(2.17-3.22)\end{array}$ & 0 & $\begin{array}{l}0.173(\mathrm{M}) \\
0.000(\mathrm{FM})\end{array}$ \\
\hline 3 & Length of Pubic bone & $\begin{array}{c}8.09 \pm 0.53 \\
(7.04-9.10)\end{array}$ & $\begin{array}{c}7.89 \pm 0.76 \\
(5.63-9.22\end{array}$ & $\begin{array}{c}8.65 \pm 0.48 \\
(6.90-8.53)\end{array}$ & $\begin{array}{c}8.46 \pm 0.47 \\
(7.75-9.13)\end{array}$ & 0.02 & $\begin{array}{c}0.363(\mathrm{M}) \\
0.204(\mathrm{FM})\end{array}$ \\
\hline 4 & $\begin{array}{c}\text { Length of Pubic Bone upto } \\
\text { acetabulum }\end{array}$ & $\begin{array}{c}6.56 \pm 0.67 \\
(6.40-9.34)\end{array}$ & $\begin{array}{l}6.56 \pm 0.62 \\
(5.61-7.70)\end{array}$ & $\begin{array}{c}7.30 \pm 0.33 \\
(7.91-8.98)\end{array}$ & $\begin{array}{l}7.11 \pm 0.48 \\
(6.35-7.76)\end{array}$ & 0 & $\begin{array}{l}0.968(\mathrm{M}) \\
0.062(\mathrm{FM})\end{array}$ \\
\hline
\end{tabular}

\section{DISCUSSION}

Skeletal characteristics are highly variable amongst different populations. Specific morphometric and morphological standards are required for each population to optimize the accuracy of forensic identification $[17,21]$. The present study aimed to compare the significance of metric parameters of the pubis of hip bone in sexing among the North Indian population.

Mid Pubic Width: As seen in Tables I, the midpubic width in the present study was more in males as compared to females, although the difference was statistically insignificant. On comparison between the two sides, the values were higher towards left side in both the sexes, difference being again statistically insignificant. Studies by Steyn and Iscan [22] on modern Greek population, Milne [23] on Calcutta population \& Dixit et al [21]on Delhi population also recorded the midpubic width to be significantly more in males as compared to females, thus they were in consonance with the findings of the present study.

Another study by Shukla et al [24] observed the Mid Pubic Width as $2.69(2.0-3.18) \& 2.59$ (2.11 - 3.21) in Males and $3.02(2.21-3.84) \& 2.97$ $(2.18-3.94)$ in Females on Right and Left sides respectively in Indian Population. Although this study was also done on Indian population, but in this the pubis was found to be wider in females. Similar observation was also made in a radiological study of Iranian population of Trehan region, by Memarian et al, [25] who found the mid pubic width values to be significantly more in females $(3.15 \pm 3.59)$ as compared to males $(2.74 \pm 3.53)$. Thus contradictory observations are made regarding this parameter in different studies, making it less reliable for sex determination. Similar opinion is given by Memarian et al, [25] that it is less accurate for determining gender.

Length of Pubic Crest: Table I shows that pubic 
Table 2: Comparison Of Pubic Length.

\begin{tabular}{|l|c|c|c|}
\hline \multicolumn{1}{|c|}{ Authors } & \multirow{2}{*}{ Race } & \multicolumn{2}{c|}{ Pubic Length (cm) } \\
\cline { 3 - 4 } & & Males(n) & Females(n) \\
\hline Kimura (1982) [26] & Japanese & $6.55 \pm 3.68(52)$ & $6.93 \pm 3.71(51)$ \\
\hline Kimura (1982) [26] & American Whites & $7.06 \pm 4.30(50)$ & $7.36 \pm 4.80(52)$ \\
\hline Kimura (1982) [26] & American Blacks & $6.66 \pm 4.50(49)$ & $7.02 \pm 3.68(48)$ \\
\hline Okoseimiema \& Udoaka (2013) [27] & South Nigerian & $7.49 \pm 5.51$ & $8.44 \pm 6.73$ \\
\hline Oladipo et al (2014) [28] & Nigerian & $9.19 \pm 17.76$ & $10.31 \pm 13.11$ \\
\hline Theresa et al (2014) [29] & Lagos & $6.87 \pm 9.62$ & $7.66 \pm 8.48$ \\
\hline Kumari \& Singh (2016) [30] & Jharkhand & $6.6 \pm 8.6(24)$ & $6.68 \pm 7.6(17)$ \\
\hline Memarian et al (2017) [26] & Iran (Trehan) & $8.21(100)$ & $8.73(100)$ \\
\hline Mostafa et al (2017) [31] & Egyptian & $93.3 \pm 4.8(\mathrm{R})$, & $84.2 \pm 3.8(\mathrm{R})$, \\
\hline Present Study & North Indians & $7.92(80)$ & $8.56 .5 \pm(20)$ \\
\hline
\end{tabular}

crest was significantly longer in females as compared to males in the present study. When compared between the two sides, it was more on left side in males but on right side in females. However the difference was statistically insignificant in both the sexes. In a study by Shukla et al [24] on Indore population the pubic crest length was $1.98 \& 1.7 \mathrm{~cm}$ in males \& $2.28 \&$ $2.40 \mathrm{~cm}$ in females on right \& left sides respectively, thus being longer in females on both the sides.

Length of Pubic Bone: The authors of the present study have already discussed regarding the dimorphism in pubic length in their previous study [26]. Further comparative data has been added in Table II. It can be observed that in almost all the assessable literature, the pubis is longer in females as compared to males except in the study by Mostafa et al [32] on Egyptian population.

Length of Pubic bone up to acetabulum: As can be seen in Table I, the mean values were significantly more in females as compared to males. However no significant difference could be found with respect to side, in either sex. Steyn and Iscan [22] had measured this distance in Modern Greek population and named it as the Pubic Length for which they recorded the values to be $7.035 \pm 4.48$ in males and $7.32 \pm 4.37$ in females, thus again being more in females.

Earlier Mobb \& Wood [33] studied this length not only in humans but also in lower primates, and inferred that the pubic length is not universally more in females of lower primates. While in Cercocebus, Papio and Gorilla it is distinctly more in larger and robust male skeleton; in Pan it is almost equal. However in other primates including man, it is more in females.

Mobb \& Wood [33] further held the passage of a relatively large newborn fetal head responsible for pubic elongation in females. This, they attributed to either increased encephalisation so that newborn head is larger as compared to newborn body weight or to an increase in overall size of newborn so that newborn body weight represents a higher than expected proportion of adult female body weight. Another reason given by Mobb \& Wood [33] for increased pubic growth in females was a response to enlarge the otherwise narrowed pelvic inlet.

For all the studied parameters for the pubis of hip bone, it can be seen that there is a difference between the values of the present study and that of other workers which could be explained on the basis of ethnic and racial variations. A detailed knowledge of various parameters of the pubic bone is thus important for the anatomists, forensic experts, anthropologists, and orthopedicians as these values are geographically variable and sexually dimorphic too [34].

\section{CONCLUSION}

The overall goal of this study was to generate data of the parameters of pubis, which would help the forensic experts in specimen identification and sex determination from skeleton remains. It would also be valuable for the anthropologists in their racial and population studies [34].

\section{Conflicts of Interests: None}




\section{REFERENCES}

[1]. Singh S, Raju PB. Identification of sex from the hip bone- demarking points. J Anat Soc India 1977;26:111-7.

[2]. Issac B. Biometry of the posterior border of the human hip bone: Normal values and their use in sex determination. J Anat Soc India 2002;51:43-6.

[3]. Stewart TD. Medicolegal aspects of the skeleton, age, sex, race and stature. American Journal of Physical Anthropology. 1948; 6:315-321.

[4]. Krogman WM. The human skeleton in forensic medicine Philadelphia: J.B. Lippincott Company, 1949.

[5]. Singh S, Singh SP. Identification of sex from tarsal bones. Acta Anatomica. 1975; 93:568-573.

[6]. Abhishek Prasad Sinha et al. Morphometric study of distance between posterior inferior iliac spine and ischial spine of the human hip bone for sex determination Int J Res Med Sci. 2014; 2(2):718-720.

[7]. Black TK 3rd. A new method for assessing the sex of fragmentary skeletal remains: Femoral shaft circumference. Am J Phys Anthropol 1978;48:227-31.

[8]. Romanes GJ. Cunningham's Manual of Practical Anatomy: Upper and Lower Limbs. Vol. 1. $15^{\text {th }}$ ed. Hong Kong: Oxford University Press; 1993.

[9]. Bernbeck R. Vergleichend-anatomische Unter suchungen zum problem des aufrechten Ganges und des spezifischen Geburtsmechanismus beim Menschen. Naturw. Diss. (cited from Martin, R. and Saller, K.: Lehrebuch der Anthropologie. 1952, 556. Gustav Fischer Verlag, Stuttgart, 1957.

[10]. Chhibber SR, Singh I. Asymmetry in muscle weight and one-sided dominance in the human lower limbs. J Anat 1970;106:553-6.

[11]. Singh I. Functional asymmetry in the lower limbs. Acta Anat (Basel) 1970;77:131-8.

[12].Ferembach D., Schwide ky I., Stloukal M.Recommendations for age and sex diagnoses of skeletons. J of Hum. Evol. 1980; 9: 517-549.

[13]. Ali RS, Maclaughlin S. Sex identifi cation from the auricular surface of an adult human ilium. International J. of Osteoarchaeology. 1991; 1: 57-61.

[14]. Bruzek J. A method for visual determination of sex, using the human hip bone. Am J Phys Anthropol. 2002; 117: 157-168.

[15]. Phenice TW. A newly developed visual method of sexing the os pubis. American Journal of Physical Anthropology.1969; 30(2):297-301.

[16]. Takahashi H. Curvature of the greater sciatic notch in sexing the human pelvis. Anthropological Science. 2006;114(3):187-91.

[17]. Nagesh K, Kanchan T, Bastia BK. Sexual dimorphism of acetabulum- pubis index in South- Indian population. Legal Medicine. 2007; 9(6): 305-8.

[18]. Day MH, Wilmott RW. Sexual differentiation in the innominate bone studied by multivariate analysis. Annals Human Biol 1975; 21: 143-151.

[19]. Seidler H. Sex-diagnosis of isolated os coxae by discriminant functions. J Human Evol 1980; 9: 597-600.

[20]. Schultz AH. The skeleton of the trunk and limbs of higher primates. Human Biol 1930; 2: 303-438. Cited by Washburn SL. Sex differences in the pubic bone. Am J Phys Anthropol 1948; (6): 199-207.
[21]. Dixit S, Kakar S, Agarwal S, Choudhry R. Sexing of human hip bones of Indian origin by discriminant function analysis. Journal of Forensic and Legal Medicine. 2007; 14(7):429-35.

[22]. Steyn M and Iocan MY. Metric sex determination from the pelvis in modern Greeks. Forensic Sci Int 2008;179(1):86.e1-6.

[23]. Milne N. Sexing of human hip bones. J Anat. 1990;172: 221-226.

[24]. Shukla SN, Prasad A and Kumar A. Analysis of various parameters of hip bone for determination of sex. Indian Journal of Clinical Anatomy and Physiology, January-March, 2017;4(1):20-25

[25]. Memarian A, Aghakhani K, Mehrpisheh S and Fares F. Gender determination from diagnostic factors on anteroposterior pelvic radiographs. Journal of the Chinese Medical Association 2017; 80:161-168

[26]. Sachdeva K, Singla RK and Kalsey G. Role Of IschioPubic Index In Sex Identification From Innominate Bones In North Indian Population.Int J Anat Res 2014, Vol 2(3):515-20. ISSN 2321- 4287

[27]. Kimura K. Sex Differences of the hip bone among several population. Okajimas Folia Anat. Jpn., 58 (4-6) : 265-276, March 1982

[28]. Oladipo GS, Anugweje KC. Ischio-pubic Index of a Nigerian population residing in Rivers state. Current Trends in Technology and Science 2014;3(2):80-5.

[29]. koseimiema SC, Udoaka Al. Radiological Determination of Ischio-pubic Index in South- South Nigerian Population. Asian Journal of med Sci. 2013; 5(5):96-100.

[30]. Theresa BE, Ekaette JA, Mesembe OE. A study of Ischio-pubic index using X-ray films in Lagos state of Nigeria. Hindawi publishing corporation Volume 2014, Article ID 192897, 4 pages. http:// dx.doi.org/ $10.1155 / 2014 / 192897$.

[31]. Kumari S, Singh B. Determination of Sex by Quantitative Analysis of Ischium and Pubis in the Population of Jharkhand. Indian Journal of Forensic Medicine and Pathology. 2016; 9(3),93-100.

[32]. Mostafa EMA, Gad AAM, Hashish RK, Dessouki SKM and Khafagy AAM. Sex determination using threedimensional computed tomography of pelvis measurements in adult Egyptian population. European Journal of Forensic Sciences 2017;4(2):21-25

[33]. Mobb GE and Wood BA. Allometry and sexual dimorphism in the primate innominate bone. Am J Anat 1977; 150: 531- 538.

[34]. Shathviha PC, Babu KY and Mohanraj KG. Assessment of sexual differences in the bony pelvis by pelvimetry using simple morphometric parameters. Drug Intervention Today 2018; 10(10): 1939-1942.

How to cite this article: Kanika Sachdeva, Rajan K Singla, Gurdeep Kalsey. ROLE OF PUBIS IN SEXUAL DIMORPHISM OF HIP BONE - A MORPHOMETRIC STUDY IN NORTH INDIAN POPULATION. Int J Anat Res 2020;8(2.1):74307434. DOI: $10.16965 /$ ijar.2020.121 